\title{
LA CULTURA DE LOS MORISCOS VALENCIANOS
}

\author{
Ana Labarta*
}

La sociedad "morisca" en general ha sido objeto de atención desde el mismo siglo XVI y ha originado un océano de bibliografía que aborda muchos de sus aspectos, entre ellos la dificultad de la sociedad dominante para imponerles su religión cristiana, su lengua romance y sus leyes romanas.

En el presente trabajo voy a ocuparme sólo de los moriscos valencianos, porque son los que conozco mejor de primera mano, a través de sus documentos y material de archivo; y hablaré de su cultura, atendiendo a la propuesta que me han hecho los organizadores del presente homenaje.

Antes de empezar convendrá que explique qué entiendo por cultura. Sigo a Mosterín, quien define la cultura como "la información transmitida por aprendizaje social entre animales de la misma especie" en oposición a lo natural que es "la información transmitida genéticamente". La cultura es todo lo que deriva de la creación humana y se transmite por imitación, mientras que los procesos naturales tienen lugar y se transmiten de manera mecánica. Según estos planteamientos, son cultura todas las obras, ideas y actos humanos no naturales.

Así pues, la cultura -tal como se entiende actualmente- es el conjunto de todas las normas con las que una sociedad regula el comportamiento de las personas que la integran, en todas sus facetas y aspectos. Es también el conjunto de los conocimientos, informaciones y habilidades que posee el ser humano, pero no sólo: incluye todas las creencias, costumbres y prácticas, sociales e individuales, públicas y domésticas. De manera que debemos considerar "cultura" el conjunto de todas las manifestaciones humanas; es una característica universal, que poseen todas las sociedades en cualquier lugar y época, si bien sus rasgos pueden diferir de una a otra y modificarse dentro de una misma.

La cultura de la comunidad musulmana valenciana tenía unos rasgos que se habían venido transmitiendo de padres a hijos y que en buena parte llegaron hasta la época que aquí nos ocupa y que denominamos "morisca", es decir, el periodo que va desde el bautismo obligado de 1526 hasta la expulsión de 1609. Algunas de aquellas antiguas pautas se habían visto modificadas a partir de la

\footnotetext{
* Universitat de València.
} 
llegada de Jaime I (m. 1276) con la imposición por parte de la autoridad pública cristiana de una serie de superestructuras políticas, sociales, administrativas y fiscales. En las fechas posteriores, la presión política, económica y religiosa del grupo cristiano dominante intentó modificar más a fondo otras muchas pautas culturales de la sociedad morisca. El bautismo impuesto en 1526 marcó un punto importantísimo de inflexión, ya que a partir de esa fecha quedaron prohibidas todas las manifestaciones religiosas musulmanas, la aplicación de la ley islámica y las instituciones comunitarias inspiradas en ella.

Pero la cultura está constituida por muchos más elementos que la religión y los aspectos de la vida relacionados con ella. Además, para que se dé un proceso de cambio cultural es preciso que la comunidad en cuestión perciba la acción o característica nueva como preferible a la anterior, que entonces abandonará. Las autoridades españolas pretendieron obligar a la comunidad morisca a dejar sus rasgos culturales propios sin haberle aportado y hecho asimilar antes unos elementos culturales alternativos apetecibles que sustituyeran a los que se les prohibían; intentaron hacerles adquirir de manera forzosa determinados patrones culturales extraños, extranjeros, que a menudo estaban en contradicción con sus tradiciones. La consecuencia fue la que era lógico esperar: no consiguieron su propósito, sino una colección de delitos y procesos.

\section{FUENTES}

Para conocer una sociedad ya desaparecida hemos de acudir necesariamente a las fuentes escritas y a las manifestaciones arqueológicas y artísticas conservadas. Podemos acceder así sólo a una aproximación muy limitada y parcial; en el caso de los moriscos, aparte de la documentación en árabe escrita por ellos mismos, la mayor parte de las fuentes de que disponemos corresponden a la visión del otro grupo: normas del rey, procesos civiles, criminales o inquisitoriales, que nos dan noticia de los nombres y acciones de los infractores y de los castigos impuestos y por tanto nos dan información sesgada.

Una de las fuentes que mejor conozco y que he trabajado desde hace tiempo es el conjunto de procesos inquisitoriales y causas de fe contra moriscos valencianos que se custodian en el Archivo Histórico Nacional de Madrid. No es una fuente primaria, porque los testimonios moriscos fueron redactados por secretarios que escribían en castellano lo que los protagonistas explicaban en sus declaraciones, traducido a veces del árabe mediante intérprete y otras muchas resumido o parafraseado. Pero en el curso de la narración se recogen al paso expresiones, aclaraciones, datos y pequeñas noticias que nos van dando briznas de información sobre el comportamiento de aquella sociedad. En la exposición que sigue voy a documentar algunos aspectos de la cultura morisca a través de citas extraídas de las fuentes inquisitoriales.

Lo cultural afecta a todas las facetas de la vida, hasta incluso a las que pueden parecer más insignificantes. En un contexto asfixiante en que cada gesto, 
cada palabra, cada silencio era analizado con lupa por la comunidad cristiana, buscando una pista de conducta musulmana, los testimonios ante la Inquisición revelan multitud de rasgos culturales propios de la comunidad morisca; no todos son religiosos, aunque tal parecían a los ojos de los delatores porque no coincidían con sus propios patrones de actuación.

La simple curiosidad antropológica podía resultar nefasta: sor Margarita Roda, monja del monasterio de la Encarnación en Valencia fue procesada en 1531 bajo la acusación de que "tenía amistad con un moro y su madre, se avia alheñado y comido cosas y adreçado y cozinado de moros; y havia ydo a ver como parían las moras y cómo enterravan los muertos y baylavan" (555/3).

El elemento discordante entre las dos sociedades puede deberse a que una forma cultural contrasta con la otra por tratarse de soluciones diferentes a un mismo problema: hablar árabe o hablar castellano; freír con aceite o freír con manteca de cerdo; rezar determinadas oraciones o rezar otras; la manera de degollar o matar los animales; la manera de sentarse...

Pueden manifestarse por acciones positivas en que el rasgo que nos interesa está presente entre los musulmanes y ausente entre los cristianos, como sería estar circuncidados los hombres, lavarse (¡incluso en invierno!), comer carne los viernes o en Viernes Santo.

$\mathrm{O}$ a la inversa, el elemento cultural marcado puede estar ausente entre los musulmanes y presente entre los cristianos, que comen durante el Ramadán, van a sermones y acuden a misa entre semana. Pedro Ximi, de Pedreguer, dijo que: "No había entrado en la iglesia en su vida, ni pensaba [...] y no se bolvería christiano aunque le cortasen con unas tigeras y le hiziesen pedaços" (libro 936 [1577] 150).

\section{LA LENGUA, LECTURA Y ESCRITURA}

La población morisca del Reino de Valencia conservó mayoritariamente hasta la expulsión el uso de la lengua árabe. Así lo señalan las referencias contemporáneas y las sucesivas medidas proyectadas por las autoridades con el fin de erradicarla. La mayoría de las moriscas procesadas por la Inquisición valenciana necesitó un intérprete para poder declarar. En árabe están los documentos y firmas escritos por esta comunidad a lo largo de todo el siglo XVI y principios del XVII; y se han conservado varios cientos de ellos. Carmen Barceló editó 211 textos árabes en sus Minorías islámicas en el País Valenciano, en el libro Archivos Moriscos hemos editado conjuntamente otros 177; y tenemos en estudio muchos más aún inéditos.

Respecto a la situación ligüística, es bien conocido el testimonio del jesuita contemporáneo Ignacio de las Casas, quien decía (f. 19 r-v) que: "los [moriscos] de Valencia hablan la lengua arábiga y son raros dellos los que entienden bien la española o sean capaces de un razonamiento o discurso principalmen- 
te en cosas de la fe por muy ladinos que sean; los más deste reino saben leer y escrevir su lengua arábiga, tienen escondidos muchos libros de su secta, ritos y ceremonias; sustentan / / alfaquíes que se la enseñan".

Los datos que tenemos sobre esta zona parecen indicar que en las áreas rurales la población era arabófona monolingüe, mientras que había cierta tendencia al bilingüismo en las ciudades. Muchos hombres tenían conocimientos de romance, pero eran raras las mujeres que hablaban más lengua que la árabe. Como parece lógico, el monolingüismo árabe se mantenía en proporción inversa a los contactos entre moriscos y cristianos viejos.

Se trata de un grupo que habla árabe de tipo magrebí, en la variedad andalusí, con peculiaridades propias de la época y zona ${ }^{1}$.

Conservar la lengua árabe era uno de los rasgos culturales que caracterizaban a la comunidad morisca valenciana, una seña de identidad a la que no estaban dispuestos a renunciar. En 1604 Ángela Palaua, vecina de Mislata, dijo que "primero moriría que dejase su algaravía" (libro 938 [1604?] 283). Por las mismas fechas Ángela Rabaça, de Vallés y vecina del arrabal de Xàtiva, declaraba que "fue mora y no hiço otra cosa más de hablar en algaravía" (554/12), de donde se desprende esa vinculación entre "ser mora" y "hablar árabe" que tanto molestaba a las autoridades.

Es una sociedad alfabeta y diglósica, que intenta escribir en árabe literal, y en la que muchos de sus miembros llevan en árabe libros de cuentas y escriben mensajes y cartas. Como narra un testigo "quando tienen la pasqua o quaresma de moros le embian al dicho Çoayat Muça de otros lugares cartas en algarabía avisándole de como es ya la pasqua o quaresma para que dé aviso a los otros lugares que ayunen y hagan las ceremonias de moros y así él da aviso a los de Chiva y a otros lugares" (553/15 Miguel Muza vecino de Chiva, s.a.).

Los moriscos leen y copian libros, los aprecian, compran, venden y poseen. Y no tienen sólo ejemplares del Corán, sino también obras de distintas temáticas: tradiciones religiosas, derecho, gramática, textos médicos y científicos ${ }^{2}$. De hecho están a la última en bibliografía y si necesitan algún libro que no tienen no dudan en hacérselo traer de Argelia. Catherina Mandarany, mujer de Antonio Amarel, de Carlet, declara que "su marido desta save leer y escrivir y tiene muchos libros en una arca o cesta" (554/19, 1602). Alonso Lapeña, dulzainero de Domeño, tenía en 1599 dos libros; una vez vistos por un experto resultó que "el uno dellos era de sirurgia y el otro de cuentas" (552/30).

Algunos incluso se atrevían a hacer composiciones literarias y sabemos que circulaban poemas en alabanza de Mahoma, romances y canciones de te-

1. Puede verse la caracterización del dialecto andalusí en CORRIENTE, 1992; las peculiaridades del dialecto árabe valenciano en BARCELÓ, 1984 y LABARTA, 1986.

2. Hemos dado amplia información sobre los manuscritos que circulaban entre los moriscos valencianos y los que se han conservado de entre ellos en Barceló y Labarta, 2009: 56-76. 
mática diversa: Juan Sastret, de Piles, dijo en 1587 de un librito que le habían encontrado "que eran unos romances de Meliquet bandolero que mataron otros bandoleros" (555/14). A Pedro Barber, de Albalat, "le hallaron unas coplas en arávigo que contenían ciertas ynvocaciones de Mahoma” (libro 936 [1581] 307).

Circulaban además libros de polémica religiosa contra los cristianos. Miguel Muza, vecino de Chiva, "leya un día un libro en algarabía delante de muchas personas, el qual libro contenía una disputa de Mahoma con un cristiano que dezía cómo Mahoma abia vençido al cristiano, y dixo a los que le oían 'veis como vale más la ley de Mahoma que no la de los christianos' e [...] mostró mucho plazer y alegría dello [y dijo:] ¡O malaventurados de christianos, como van çiegos en su ley!” (553/15, s.a.).

Las fuentes inquisitoriales señalan cuidadosamente de cada procesado si sabía o no leer y escribir en árabe y en romance. Nos informan así de que algunos conocían el alfabeto latino y tenían también libros en romance. Francisco Torromani, justicia del lugar de Atzeneta, en el condado de Albaida, "dixo [en 1574] que sabe leer letra de emplenta y que no sabe screvir en castellano y que en arábigo sabe leer y escrevir y que no tiene libros si no es una doctrina christiana y otro librito y en su casa tiene un libro de San Vicente Ferrer y otro de Sant Agustín y un libro de albeytería y unos libros de yngüentes de moros y también tiene libros de medizina" (555/31). También Hierónimo Escatrón, tagarino afincado en Paterna, declara en 1577 que "sabe leer un poco en letra de imprenta y que tiene libros de romance en que hay romances y doctrina" (556/7).

Los inquisidores consideraban como prueba de cargo el hecho de que los moriscos poseyeran y leyeran libros en árabe; involuntariamente los testimonios de las acusaciones incluyen datos preciosos sobre la enseñanza que permiten entrever cómo eran las clases, que las mujeres no estaban excluidas del saber, o que los niños usaban las mismas tablas-pizarra que se utilizan aún hoy. Un testigo declara (1602) que Amanet "enseñava la secta de Mahoma; tenía como ocho o nueve libros de la secta de Mahoma y le vio leer en ellos y quando les enseñava los repartía entre los demás que le oýan y los dichos libros los tenía en un agujero de la pared de la cocina" (554/19). Otro dice que Miguel Muza, de Chiva, enseña a "ciertos mochachos que declaró la secta de Mahoma y cosas del Corán como son las oraciones del andurulehi y collua y a bisto salir muchas vezes los dichos mochachos de casa del dicho Muça con sus tablillas de deprender" (553/15, s.a.). Patrel, jabonero de Carlet, también daba clases por las noches a otros moriscos y a tres hermanos y una hermana que tenía "y el dicho Patrel tiene libros de la secta y [...] los tenía en una andana donde crían gusanos; y algunas vezes los metía debajo de una tinaja donde metían ropa" (554/19, 1602). 


\section{LAS PRÁCTICAS RELIGIOSAS}

El bautismo forzoso no supuso la conversión al cristianismo de la comunidad musulmana; simplemente convirtió en delito sus creencias, sus prácticas y todos los aspectos de la vida relacionados con ellas. Sobre el Islam y sobre la vida religiosa de los moriscos en general hay una amplia bibliografía; sigue siendo útil la obra de Longás, que nos exime de entrar aquí en más detalles.

Ignacio de las Casas, en un informe a la Inquisición, dibuja en un breve bosquejo los principales aspectos religiosos: "los [moriscos] de Valencia -dice[...] tienen escondidos muchos libros de su secta, ritos y ceremonias; susten$\tan / /$ alfaquíes que se la enseñan y los circuncidan y resuelven sus dudas; éstos los casan a su rito y fueros y les hazen su carta de dote; guardan claramente su Ramadán ayunando toda su luna y celebran sus pascuas; tienen por honrra el ser castigados por la guarda de su secta y hallan después sólo por esto más honrrosos casamientos y el día que salen al aucto o à recebir otro qualquier castigo se ponen tocadores o toquillas muy limpias y blancas en señal de su innocencia y de padecer por su fe" (f. $19 \mathrm{r}-\mathrm{v}$ ).

Esta cita trae a la memoria un caso acaecido en 1577 cuando las autoridades ahorcaron al morisco Luis Hemça en Alberic. Mientras salían "para sentencialle deçia a boçes altas en algaravía que le perdonasen e que hiciesen testimonio que moría como buen moro, [...] diciendo esto todo el camino [...] e quando fueron en la horca antes de subirle dixo en algaravía que moría como buen moro y después estando arriba para echarle el verdugo dixo en nuestra lengua en aljamía a boçes altas para que todos lo entendiesen que su padre murió como moro y que él moría como buen moro". Días después el Santo Oficio escribía a Alberic para que investigaran "qué moriscas an ydo y van a pasar por su horca como quien va a ver cuerpo sancto porque murió moro; y V. M. lo mandará descolgar y hazer poner el cuerpo en lugar señalado" $(551 / 33,1577)$.

Evidentemente, lo que interesaba a los inquisidores eran los delitos "contra la fe", es decir, los que se derivaban de no practicar el ritual católico y seguir practicando el ritual musulmán. Por ello las acusaciones que se repiten son las que corresponden a la persecución de los ritos básicos del Islam: abluciones, oración, ayuno; documentos legales (como acidaques o cartas de dote y reparto de herencias) y costumbres como la circuncisión o los ritos de lavado del cadáver, oraciones mortuorias y enterramientos.

Las delaciones resultan a veces bastante gráficas, y algunas dan datos complementarios y noticias sobre rituales, no todos documentados antes: Marien Garrucho y otras mujeres de Carlet en 1573 "sacaron el cuerpo muerto del dicho Garrucho a un corral descubierto de su casa y puesto encima de una mesa le lavaron todo con agua callente y le estregavan con un esparto y después de haverle lavado la dicha madre y sus dos hijas se llegavan a los oydos del dicho cuerpo muerto y en algaravía, questa la entiende, le dezian que se encomendasse a Mahoma" (552/5). 
De Maestre Tomás, vecino de Ascó, nos cuentan que “quería abrir la sepoltura de su muger y meter en ella ciertas cosas que los moros suelen poner quando entierran alguno" (libro 936 [1567] 32). A Gaspar Morrut vecino de Castellón "se le murió una niña y le puso sobre la mortaja aspa y tigeras como ceremonia de moros" (libro 937 [1590] 229).

La persecución alcanzaba también a los señores que tenían vasallos moriscos y les consentían continuar con sus costumbres después de la prohibición: así Rodrigo Muños, señor de la baronía de Ayódar, fue procesado por la Inquisición "por haver dado licencia que los moros hiziessen particiones de sus haziendas a uso y costumbre de moros" (libro 936 [1574] 114).

No conocer las oraciones cristianas era un rasgo que delataba pertenecer a la comunidad musulmana; pero la diferencia entre los rituales se manifestaba también en rasgos no-verbales y aparentemente inocentes, como la manera de arrodillarse: Miguel Rocaiz, de Castellón de Rugat, "no supo signarse ni santiguarse y no supo cosa de christiano más que unas palabras mal concertadas del Ave María y se yncó de rodillas sobre los talones como moro" (554/24, 1596). Nofre Azmet Çuleydel, de Campell, "preguntado por las oraciones, sentóse sobre los talones, qu'es cerimonia de moros; no supo signarse ni santiguarse ni oraçión ninguna de christiano y se bolvió a sentar como moro sobre los talones" (549/30, 1590).

\section{LA DEVOCIÓN POPULAR: JACULATORIAS}

Los aspectos religiosos musulmanes normativos están descritos en todos los manuales de buen inquisidor y muy tratados en la bibliografía morisca. Es poco, por el contrario, lo que sabemos sobre las devociones populares que, aun teniendo una base islámica, están animadas por otros condicionantes no regulados por la ley religiosa. Entre los rasgos culturales que podemos relacionar con la religiosidad popular están las jaculatorias que se dicen (o no) y los gestos que acompañan el bostezar, estornudar o toser o que se dicen al vérselo hacer a otro, al acostarse o al desperezarse.

A Pedro Boris, de Cocentaina, un testigo "le havia visto quando bostezava, en lugar de la cruz que hazen los cristianos, meter en la boca los cinco dedos de la mano en remembrança de la hamça que son los cinco mandamientos de Mahoma" (libro 938 [1604?] 273). De un golpe, el testimonio señala la discrepancia entre los dos grupos religiosos y describe qué hacía cada uno de ellos. Catalina Martínez Buxa, viuda de Miguel Sebastián, “quando bosteçava se encomendaba a Alá como los moros lo dezian” (libro 936 [1583] 352). Maria de Liria "quando bostezava, fue oyda dezir «Ley Alla»" (libro 936 [1583] 383), es decir, "no hay más divinidad que Dios", base del testimonio de fe islámico.

Entre ambas comunidades discrepa también la manera de saludarse. Un testigo vio a Miguel Gamir, vecino de Teruel, "saludarse con otro morisco va- 
lençiano a usança de moros" (libro 936 [1583] 351). Vicente Verdura, de Xeresa, le dijo en 1588 a Jaime Dordo "en algaravía: «Dios os guarde, tío»" (550/3).

Hamet, de Benipescar, dijo desperezándose: "«açala hali Mahomet», que significa «loor a Mahoma»" (libro 937 [1590] 229).

Esta misma jaculatoria (al-ṣalà 'alà Muhammad) fue la que dijo Carmelia, mujer de Carchet, de Otos, que "imprimió la mano en la masa y dijo «açala Mahomet»" (libro 937 [1590] 223).

Los cristianos se santiguaban al acostarse, y tal vez dijesen también alguna oración. Hierónima Palleres de Albero, cristiana vieja, declara que Ángela Rabaça, vecina de Vallés, "la ayudaba en la asienda de los gusanos de la seda; haviendo quedado a dormir en su casa la dicha Ángela Rabaça en compañía de una ama que se dise Maginera, al día siguiente le preguntaron que por qué no se santiguó antes de acostarse y la importunaron hasta que dijo que los christianos yvan enganyados y que si se bolviezen moros sería mejor y que Mahoma puede mucho y que a ellos los tiene gordos y buenos comiendo mal y teniendo trabajos y que nosotros con regalos y contentos siempre estamos enfermos y que nuestra senyora la virgen María no era virgen" (libro 938 [1607] 358 y 554/ 12).

Dos mujeres juraron que no habían entrado a segar alfalfa en un sembrado de Gaspar Alcadi, vecino de Bélgida, "y lo juraron por la cruz, haciendo señal con los dedos"; él dijo "que no creía en la cruz ni en la cristiandad" (libro 938 [1602] 210) por lo cual fue procesado; pero lo que nos interesa es el gesto y la fórmula de las cristianas que juran "por la cruz" al tiempo que hacen una cruz con los dedos. Los moriscos son acusados de jurar de manera inadecuada porque lo hacen en árabe y con expresiones religiosas musulmanas como al-ṣalā 'alà Muhammad o pronunciando la profesión de fe islámica. La mujer de Mean, vecina de Castellón, juró diciendo " «çala hali Mahomet», que significa «por vida de Mahoma»" (libro 937 [1590] 235); Gerónima Humarri, vecina de Castellón, "por vida de Mahoma: por «hale sala Mahomet»" (libro 937 [1590] 229); Francisco Barragán Porrino, de Matet, juró "por vida de Mahoma" (libro 938 [1602] 176); la mujer de Dobet, de Castellón, dijo "por la fe de Mahoma" (libro 937 [1590] 235); Gerónima Gorba, vecina de Castellón, “juraba por Mahoma diciendo «hale hala Mahomat reçuçala»" (libro 937 [1590] 229).

Hay otro tipo de juramentos: Joan Axeret, vecino de Otos, dijo "por el alquible açia do tengo buelta la cara" (libro 937 [1590] 230); Esperança Bolinche dijo "por las palabras del Alcorán verdadero que tal no dije" (libro 937 [1575] 751); y Luis Puntero, vecino de Navajas, juró "por los sesenta capítulos del Alcorán" (libro 938 [1597] 40).

La alegría se muestra con la jaculatoria al-hamdu li-llāh, esto es "gracias a Dios". Eso dijo Miguel Cortrell, del arrabal de Gandía, cuando se enteró de que habían asesinado a unos moriscos delatores: "alhanduruley, ya tenemos tres muertos" (937 [1591] 363).

Más difícil resulta saber qué decían para manifestar el dolor. Mientras azotaban por la calle por ladrón a Miguel Mayoral, de Callosa, invocaba a Ma- 
homa en árabe diciendo "ala çahali Mahomad, que interpretado quiere decir «ayúdame Mahoma»" (938 [1599] 51). Parece que se trata de la misma expresión al-șalät 'alà Muhammad.

María Aldamis, de Jarafuel, cuando, procesada por la Inquisición, estaba en el tormento "gritava y dezia que tenía el braço cortado y la mano cortada y que Dios sea con ella, repitiéndolo en algaravía" (550/11, 1602), pero en el proceso no se transcriben las expresiones árabes usadas por la pobre mujer. La vecina de Pinet, Ysabel Buney, que durante su proceso en 1595 había declarado mediante intérprete, a la hora del tormento "daba grandes gritos y decía «madre de Deu» muchas vezes" (549/15), al parecer en romance, acción que tal vez buscara la benevolencia de los inquisidores.

La sorpresa se manifiesta con la misma jaculatoria tantas veces repetida ya: el árabe al-ṣalā 'alà Muhammad. La expresión está transcrita de manera diferente en la acusación, en la ratificación y en el resumen del proceso contra Francés Aquem, vecino de Alcodar. Estando preso, al ver unos grillos dijo "ala çala mahomet y qué de grillos" que según el testigo significa "válame Mahoma" (libro 938 [1602] 169); también se anotó "açala ala Mahemet qué montón de grillos"; en la ratificación consta "alaçala ale Mahemet". El padre Ignacio de las Casas interpretó las palabras arábigas del condenado: "son un modo de que usan los moros de sujección y professión de su secta y que nadie usará de las dichas palabras que no la guarde y quieren dezir 'las oraciones sean sobre Mahoma'" (548/15).

Miguel Xafer, del arrabal de Oliva, en 1593 fue con Bartolomé Curt a trabajar en sus heredades, que las tenían próximas. Éste se subió a una higuera y comenzó a comer higos "y siendo esto en el tiempo del ayuno del Ramadán que ayunan los moros, le dixo a éste el dicho Bartolomé Curt: «jJesús! ¿Agora coméys higos? ¿No ayunáys el ayuno?» y éste le respondió que no, que no tenía cuenta con aquello porque en casa de su padre nunca abía visto ayunar" (552/38). No deja de resultar curioso que un morisco emplee el vocativo "iJesús!" como exclamación de sorpresa.

Cuando tropiezan también se les oye decir al-șalā 'alà Muhammad o alguna expresión similar: Cosme Bençalema, tropezando dijo “Dios y Mahoma sea contigo" (libro 937 [1590] 223); la viuda Moferrix, tropezando dijo açala Mahomet (libro 937 [1590] 234); la viuda de Joan Baisan, tropezando dijo "válgame Mahoma" (libro 937 [1590] 234). A María Zumi, vecina de Cofrentes, "cayéndosele una çesta de rropa que llevaba a lavar", un testigo la oyó decir "ali çala Mahomet, que quieren dezir estas palabras ynbocar a Mahoma" (libro 918 [1600] 214).

Podemos vislumbrar los gestos y las exclamaciones que salen espontáneas debido al miedo y las que se usan para pedir ayuda. La mujer de Burux, de la morería de Alzira, a la que se le quemaba una casa "dava bozes ynvocando a Mahoma" (libro 936 [s.a.] 462). A Pedro Martorell, del arrabal de Xàtiva, le encontraron unos libros y "quando fueron allados, cierta persona conjunta suya dixo en algarabía: «O desdichados de nosotros que todos somos quema- 
dos»" (552/28). Al quitarle los alguaciles una nómina en árabe a Esperança Genen, de Xàtiva en 1583, ésta decía, "dándose con las manos en la cara, «haçara, haçara»", que podría interpretarse como yā hasra, es decir "¡Ay de mí!" (551/26). María Aldamis, de Jarafuel, daba gritos "afligiéndose e lastimándose, e hablaba en algaravía"; al sacarla a la calle, la morisca se tiró al suelo gritando viafra. El testigo no entendió "más de viafra que es palabra para que se junten gentes para algún propósito". Se trata de la antigua exclamación valenciana ¡Via fora!, usada para pedir socorro a los vecinos ante algún hecho delictivo $(550 / 11,1602)$. Al margen de las expresiones verbales recogidas, notaremos que ambas mujeres muestran su aflicción abofeteándose la cara: "dándose con las manos en la cara", "afligiéndose e lastimándose".

\section{LAS SUPERSTICIONES}

Los estudiosos de los procesos inquisitoriales han atendido también a los aspectos llamados "supersticiosos". Como señalaba CARO BAROJA (1976: 125) "aun en lo que no era musulmán ortodoxo el morisco se diferenciaba sensiblemente del cristiano viejo, pues si éste recurría en múltiples ocasiones a ciertas supersticiones y hechicerías y aquél también, los conjuros, los bebedizos mágicos y las cédulas cabalísticas usadas por los moriscos [...] son harto diferentes de los que usaban los cristianos".

En el trabajo que dediqué a este tema (LABARTA, 1979) decía que las fuentes inquisitoriales no permitían detectar que los moriscos siguieran comportamientos negativos inspirados por concepciones supersticiosas, es decir, que evitaran actuar de determinada manera, considerada de mal agüero. Pero he encontrado noticia de un hecho curioso que los inquisidores consideraron "ceremonia de moros" y que parece una superstición de ese tipo: Leonor Dari, vecina de Castellón, "se quitó un zapato, cayó boca abajo y lo volvió a coger porque no muriese su padre o madre" (libro 937 [1590] 225).

La práctica más difundida entre los moriscos era la fabricación y posesión de amuletos o talismanes, que las fuentes coetáneas denominaban herces. Hay multitud de moriscos procesados por escribirlos o por llevarlos encima. El tipo más frecuente era el escrito sobre un papel que se doblaba y guardaba en una bolsita de tela, cosida y encerada, que se llevaba en el bolsillo, colgada al cuello o cosida a la ropa. El contenido textual variaba de unos a otros, aunque en general consistían en fragmentos del Corán, invocaciones a ángeles, palabras mágicas sin sentido aparente y signos como "letras con anteojos", cuadrados mágicos y estrellas de seis puntas.

Los motivos por los que los moriscos los llevaban pueden resumirse en tres tipos básicos: para curar enfermedades y dolores; como defensa y protección contra heridas; $y$ de una manera genérica como símbolo de pertenencia a la comunidad musulmana. Se ponían en la ropa de los recién nacidos, a los difuntos en el sudario, y también se metían en las paredes de las casas. 
Había además una especie de medallas, que la documentación llamaba "nóminas", "dóminas" o "patenas". Eran unas placas metálicas, al parecer de oro o plata, en las que podían verse grabados textos y dibujos del sol, la luna o una mano. Por ejemplo, en casa de Gerónimo Adulaas, vecino de las Almoinas se encontraron "unos cascaueles de plata e media luna con letras aràvigas de cosa de moros" (libro 937 [1590] 227).

Esto lleva a aludir brevemente al tema de la jamsa, que ahora conocemos como "mano de Fátima". La encontramos denominada "mano de David", dibujada en los amuletos de papel y grabada en los de metal; consta que los moriscos de Segorbe usaban una casa como mezquita y tenían allí unas esteras labradas de blanco y negro "bendecidas por el alfaquí" y en ellas estaba "pintada la hamça, que son los cinco dedos que representan los cinco mandamientos de Mahoma" (libro 938 [1608] 416).

En el mismo informe ya citado, Ignacio de las Casas contaba escandalizado: "De la mesma confiança nace el atreverse a poner ciertas manos pintadas abiertas en las paredes de sus casas o lugares que quieren y aún junto a las cruzes por befa dellas, porque aquella mano es símbolo de la su secta como la cruz de nuestra fe. Vi puesta esta mano en una cruz de piedra que está en el camino de Valencia a Segorbe y en varias partes del claustro alto de la Cathedral de aquella ciudad junto a varias cruzes y con ellas versos en arábigo en ignominia de la cruz y loa de su secta" (f. 172 r).

Con esta interpretación de la mano como símbolo de los cinco pilares de la fe musulmana, y por extensión del Islam, podemos relacionar la noticia del morisco al que habían visto "quando bostezava meter en la boca los cinco dedos de la mano en remembrança de la hamça que son los cinco mandamientos de Mahoma" (libro 938 [1604?] 273). Y los procesos de varias mujeres acusadas de imprimir "la mano en la masa" diciendo "açala Mahomet" (libro 937 [1590] 234). Carmelia, mujer de Carchet, vecina de Otos "imprimió la mano en la masa y dijo açala mahomet que quiere decir [aclaran los inquisidores] que cuando se quisiese morir llamase a Mahoma" (libro 937 [1590] 223).

\section{LA VIVIENDA}

Existen aspectos de la cultura morisca que han merecido menos atención y otros que ni siquiera se han planteado ni han sido abordados desde cualquier perspectiva.

Es cultural la manera de construir la casa, su tamaño, forma y orientación, la disposición de sus aposentos y el uso que se les da, el mobiliario, los utensilios, ropas y objetos domésticos con sus funciones, formas y decoración. Sobre la vivienda se han interesado algunos arqueólogos, que han descrito las casas que parecen haberse conservado en algunos despoblados, mientras que de otros antiguos núcleos moriscos no existen hoy trazas, ni huella de dónde estuvieron ubicados. Pero esas viviendas están vacías de mobiliario y enseres, tema que re- 
quiere una investigación interdisciplinar entre arqueólogos, historiadores y lingüistas. Poco se sabe sobre el urbanismo de aquellos poblados y de las antiguas morerías y apenas existe relación o descripción detallada de objetos de cerámica, tejidos, decoraciones o maderas de adscripción clara a la cultura morisca.

En los inventarios de bienes derivados de los procesos y en estos mismos se encuentran múltiples referencias al mobiliario y enseres, ropas de casa, esteras y elementos constructivos y de distribución interna de la vivienda que deberían recogerse y estudiarse. Las fuentes aluden a ropas de casa que califican como ropa "a la morisca", lo que permite inferir que se debían distinguir fácil y claramente de las que no lo eran, tal vez por sus colores, como sugiere el hecho de que en la casa de Joan Redondo Rabaça se hallaran "dos almohadas moriscas" (554/18 [1603] lista de bienes), en la casa de Berenguer Rabaça "dos colchones moriscos", "veinticuatro colchones moriscos" y "un cortinaje morisco" (554/ 18 bienes); también en la casa de Francisco Chuclut Maganya se encontraba "una coxinera morisca" y "un lienço para hazer colchones moriscos de colores" (554/ 18 bienes).

Parece que el interior de las mezquitas estaba pintado de color blanco y el suelo cubierto con esteras de esparto. Según testimonios acusadores, la aljama de Segorbe daba 30 ducados a la viuda Maria Xaramfa por el alquiler de su casa para que sirviera como mezquita; pagaba también a "tres mugeres pobres para que la emblanquinasen y limpiasen para las quatro pasquas del año y [...] tenían unas esteras labradas de blanco y negro [...] y en ellas pintada la hamça que son los cinco dedos que representan los cinco mandamientos de Mahoma" (libro 938 [1608] 416).

\section{INDUMENTARIA Y ADORNOS}

La manera de vestir es otro de los rasgos culturales que caracteriza a los distintos grupos humanos y que contribuye a mostrar la pertenencia del individuo a uno o a otro. Las disposiciones de la autoridad en época mudéjar establecían que los musulmanes debían llevar prendas, colores o marcas distintivas que los identificaran; tras el bautismo, por el contrario, se intentó obligar a los moriscos y moriscas a vestir igual que la población cristiana vieja (entre la que, paradójicamente, había estado de moda llevar prendas "a la morisca", tema estudiado por Bernis).

En 1526 los doce síndicos representantes de las aljamas musulmanas del reino de Valencia pactaban con el rey que "por quanto los dichos moros tienen bestidos moriscos los quales son differentes de los bestidos cristianos, señaladamente los de las mugeres, a las quales sería muy grave averlo de mudar y se perderían porque ningún provecho se podría sacar dellos", "por espacio de quarenta años no puedan ser forçados de mudar dichos bestidos" (BORONAT, 1901: I, 424).

En lo que se refiere a la indumentaria, atavíos y joyas y otros elementos del aspecto externo de hombres y mujeres de la población morisca valenciana, Car- 
men Barceló y yo hicimos una primera aproximación al tema en 1985 de la que tenemos ahora en prensa una versión ampliada. Contando, sobre todo, con los datos extraídos de la documentación inquisitorial y con las referencias a objetos que se mencionan en los textos árabes de los moriscos (cartas de dote, cuentas, inventarios de bienes, etc.) hemos confeccionado unos glosarios de prendas, tejidos, complementos y joyas en los que recogemos todas las referencias a colores, formas y calidades que hemos encontrado para cada uno de ellos.

Para 1603 tenemos el interesante testimonio del francés Joly que describe a las moriscas de Gandía: "vestidas con trajes de tela trabajada de seda, con grandes y anchas mangas abiertas por los costados, de seda de color, un pequeño sombrero sobre la cabeza, zapatos rayados en los pies y [...] tenían también sortijas de oro y plata, brazaletes y collares en los dedos y en los brazos y en el cuello, y en las orejas pendientes monstruosamente grandes" (apud BARCELÓ y LABARTA, 1985: 49). Algunas de las piezas señaladas por este visitante francés aparecen en los documentos cristianos; otras se mencionan en los textos árabes. La descripción evoca además las figuras de las mujeres moriscas que vemos en los cuadros dedicados a la expulsión ${ }^{3}$.

Dentro de un conjunto de joyas, los inventarios distinguen las que corresponden a un estilo y a otro; dicen por ejemplo "unas arracadas de oro a la christiana" o "unas otras arracadas [...] a la morisca de oro" (BARCELó y LABARTA, 1985: 69).

Lo mismo ocurre con la vestimenta: podemos ver en el ropero de una morisca "una saboyana de paño verde guarnecida de terciopelo, a la christiana fecha" o "una basquiña, a la christiana, de tafetán girasol de grana y amarillo, con guarnición de terciopelo negro" (BARCELÓ y LABARTA, 1985: 69); frente a "dos camisas moriscas" y "una camisa morisca sin mangas" (554/18 bienes en la casa de Francisco Chuclut Maganya).

Notaremos también que el aspecto de nuestros moriscos y moriscas en 1609 , tal como se puede ver en los cuadros que se pintaron para celebrar su expulsión, poco tiene que ver con la imagen que tenían los musulmanes y musulmanas de Granada y otras poblaciones de Andalucía que dibujaron viajeros extranjeros como el alemán Weiditz durante su estancia en nuestro país en 1529 (BERNIS, 1962 y BARRERA, 2007).

En este capítulo queda aún mucho por hacer; falta estudiar de manera amplia el tema de la moda y la estética complementaria femenina y masculina: maquillaje, tintes del pelo, tatuajes y perfumes, peinados, afeitado y formas de bigote y barba, por señalar sólo lo más obvio. Referencias no faltan; recordaremos aquí tan sólo a la monja de Valencia sor Margarita Roda, que tenía amistad con unos moriscos - madre e hijo- y que fue acusada ante la Inquisición porque "se avía alheñado" (555/3, 1531).

3. Pueden verse sus reproducciones en La expulsión de los moriscos del Reino de Valencia, Valencia, 1997. 


\section{COMIDA Y BEBIDA}

Son bien conocidos los preceptos musulmanes que prohíben beber vino y comer cerdo y exigen que los animales, para ser consumidos, deban haber sido degollados y desangrados siguiendo un ritual preciso; no hace falta insistir en ello.

En los procesos inquisitoriales son incontables los testimonios referentes a moriscos que se niegan a comer cerdo ("no comía tocino", "no quería comer puerco", "no comería tozino aunque le matasen", "no a comido tozino jamás", "los que comían tozino se yvan al infierno") o incluso cualquier manjar que haya tenido el más ligero contacto con él: la mujer de Rufo, de la Pobla del Duc, "estando en el horno, habiendo tocado un pan suyo con una torta de tozino, le hechó en el suelo e dixo: «mi padre moro e yo también mora»" (libro 937 [1590] 233).

Igualmente abundantes son las referencias a animales degollados "a uso de moros" y a moriscos que se niegan a comer carne que no esté sacrificada según su ritual. Bartolomé Catalán, de Murla, pidió de comer "y sacándole que comiesse de una olla que tenía carne [...] dixo que no lo quería comer, que le sacassen sardinas; y diziéndole que por qué no lo comía respondió: 'yo no como desso que vosotros coméis, que mi padre y mi madre fueron moros y también lo soy yo'" (libro 938 [1607] 486).

Comentan sin embargo los inquisidores en 1579 que "con los moriscos que confiesan degüello y niegan yntençión se hazen diligençias sobre ella porque el degüello que agora husan no es tan clara y formal çeremonia como lo manda la secta de los moros, que los moriscos la han disfraçado" (libro 936 [1579] 233, proceso contra Joan Carricha, vecino de Llombai).

También son abundantes las referencias al vino. Muchos son los que aseguran no beberlo y condenan su consumo. "El vino dura sin digerirlo treinta días en el estómago" dice uno; Anton Prince, tagarino vecino de Valencia, declara en 1581 que "no bebe vino" (554/8). Pedro Martorell, de Xàtiva dice en 1587 que "el vino habrá más de 30 años que no lo ha testado" (552/28). Pero algunos moriscos sí lo consumían: se dice de Miguel Xaraca Mahusa, de Segorbe (1579), que "quando no ayunaba, bevía vino" (552/41). Estando Gerónimo Solaz y otros en el puente del arrabal de Gandia pasaron por allí dos moros de Bellreguart borrachos; los "reprendieron porque no ayunavan, siendo el tiempo del Ramadán, y se emborrachavan" $(554 / 23,1589)$. Los que trabajaban entre cristianos bebían vino y algunos se emborrachaban con frecuencia.

Se ha de recurrir a la lectura de todos los procesos y causas de fe y otra documentación para espigar alguna noticia sobre qué comían y bebían los moriscos, tema que aquí expondré de manera breve, pues pienso desarrollarlo más extensamente en otro momento. Entre los ingredientes básicos que se mencionan vemos aceite, trigo y arroz, alubias, garbanzos, lentejas y habas, aceitunas, cebollas, queso (queso curado y queso de Mallorca)... Les vemos comer pan, nueces, castañas, higos, uvas, caña de azúcar, sardinas, huevos, gallina, pollo, perdiz, caza, liebre, conejo, cabrito, cordero, ternera. Como especias y condimentos están 
documentados el azafrán, la canela y la miel. Excepcionalmente se cita un guiso "con pebrada" que parece incorporar pimiento, un producto americano. Entre los platos ya elaborados se mencionan las empanadas de atún y unos caracoles con caldo de carne; muchos platos reciben el nombre del recipiente en que se guisan: caldero de gazpachos, olla de carne y buen número de guisos denominados "cazuela": "caçuelas de arroz", "caçuelas al horno", "caçuela de pescado".

Más difícil es intentar vislumbrar qué significado tenían para ellos esos alimentos y qué relación había entre ciertos guisos y su consumo en determinadas festividades o celebraciones. Sin profundizar ahora en el tema, sí podemos observar que hay una clara relación en la comunidad morisca valenciana entre los buñuelos y todo tipo de celebraciones y festividades (nacimientos, circuncisiones, mismarç, 27 de ramadán, fin del ramadán); las delaciones dicen: "ha echo fiestas y comido buñuelos", "hacían mucha fiesta tañendo laúdes y comiendo buñuelos". Un vecino del arrabal de Xàtiva acusa en 1596 a Catalina Mosener porque "ha visto que tienen hechos una barchilla de bunyuelos y tiene por cierto los han hecho para comer a los 27 días de la luna del ayuno" (550/32).

Al séptimo día después de la muerte de algún pariente, se hacía un convite para el que se guisaban ollas de carne en recuerdo del difunto.

Otros platos tienen que ver con la celebración de la boda. Entre las cosas que Ignacio de las Casas señala que no deberían hacer los moriscos está el comer "la mañana primera tras la boda la caçuela blanca del arroz"; cazuela a la que aluden otras fuentes, una de las cuales aclara un poco más la receta: "cazuela que llaman blanca, con gallinas y huevos y queso y otras cosas".

Con motivo de una boda los moriscos asistentes bebieron también "un beverage por amor de la serena de miel, pimienta y agua".

\section{LA FAMILIA}

Los historiadores de la Edad Moderna han utilizado la riqueza informativa de las fuentes parroquiales para confeccionar estudios sobre la estructura de la familia (CASEY, 1981; DOMínguez ORTIZ y VinCENT, 1978 y VinCENT, 2006): edad de matrimonio, hijos habidos, viudedad, segundas nupcias, índices de fertilidad, parentesco entre cónyuges, etc.

A pesar de que las bodas musulmanas ya no estaban permitidas, los moriscos continuaron concertándolas y celebrándolas y escribiendo sus cartas de dote en árabe, cartas que motivaron numerosas detenciones. Un testigo declara que "un morisco de Castilnou que se dezia el bayle viejo, Azmet o Azmen, concierta los casamientos e haze las cartas que antes se llamavan açidaques y agora se llaman memoriales de la ropa" (553/2 1581). Como es sabido, es habitual que el musulmán se case de preferencia con su prima hermana. Esta costumbre chocaba justamente con la prohibición cristiana de que primos hermanos contraigan matrimonio sin dispensa eclesiástica. Francisco de Castelví, 
señor de la baronía de Carlet y Benimodo fue procesado "por haver dado liçençias a convertidos de moros para que se casassen en grados proibidos" (libro 936 [1571] 492). Diversos moriscos fueron procesados por haberlo hecho; delataron por ejemplo a Luis Rodero porque "asiste a juntas, mató aldeeas, y se ha casado con una prima hermana suya" (555/4).

Aunque no era frecuente, entre los moriscos que tenían posibles podía darse la poligamia, prohibida ahora tras el bautismo; por eso acusaron a Francisco Hasan Chovi, baile de Algar, de estar "casado con tres mugeres" (551/32, s.a.).

Menos estudiado ha sido el tema de la sexualidad fuera de vínculo matrimonial: amancebamientos, prostitución, violaciones, homosexualidad, bestialismo... Los procesos civiles pueden arrojar tal vez más luz sobre algunos de estos aspectos, que en los procesos inquisitoriales se plantean muy someramente, aunque no faltan tampoco algunos datos. Hay una aclaración de los inquisidores que me resulta especialmente intrigante; afirman que "los moriscos usan que dos tienen una amiga y sabiendo el uno del otro" $(553 / 16,1605)$.

\section{DIVERSIONES}

Ignacio de las Casas se quejaba de los moriscos: "Venlos acudir a vandadas à cualesquier fiestas y regozijos públicos pero jamás los ven acudir a ganar jubileos ni los muy solemnes ni los ven oyr sermones ni entrar entre semana en las Iglesias" (f. 14 r).

Los aspectos más lúdicos de la sociedad morisca valenciana no han merecido hasta ahora atención suficiente. Es cierto que aquí o allá se alude a bailes a la morisca o a las celebraciones festivas de las bodas, pero ignoramos casi todo de estas danzas y de los instrumentos musicales que se empleaban. Tampoco es posible determinar qué tipo de música apreciaban ni las variedades de canto que pudieran existir, ni en qué consistían aquellos "regocijos públicos". Sí sabemos que circulaban cuadernos con canciones: Angela Carroça, de Sallent, tenía unos libros "que contenían diversas coplas y canciones en alabança de Mahoma y de su secta" (libro 938 [1607] 355); su marido, Noffre Blanch, dijo que entendía que contenían romances de cristianos (libro 938 [1607] 356).

También sabemos que la música de los moriscos era apreciada por los cristianos viejos, que no sólo constituían un público entusiasta sino que también tocaban, cantaban en árabe y bailaban con ellos. Y no me refiero a individuos marginales, sino a oficiales y señores: el licenciado Duarte Vallester, gobernador del señorío de Castelnovo "muchas vezes tanya en un laúd y cantava cantares en algaravía"; le acusan de que le han visto "baylar con las moriscas; especialmente [...] el çaguero día de Pasqua [le vieron] baylar en Almedíjar con una morisca de la mesma manera que baylan los moriscos". Responde "que es verdad que él tañe un laúd y lo ha tañido y cantado en algaravía por su deporte pero no en ofensa de nuestra santa fe" y "que muchos cavalleros ay en este reyno que tañen laúdes y cantan algaravía". "Algunas vezes a baylado con 
moriscas pero que no ay cerimonia en el baylar, e que a este confessante no se le a mandado que no taña ni cante ny bayle con moriscas" $(553 / 2,1579)$.

En una ocasión Damián Açen Dobler, cirujano de Buñol, tocaba el laúd y cantaba ante más de cincuenta moriscos (libro 937 [1587] 18).

Ángela Boxeta, natural de Elche, vagabunda, "en compañía de un cristiano viejo con el que se dezía estava casada, andava cantando por lugares de moros canciones de su seta nombrando a Mahoma y en particular una en tiempo del ayuno del Ramadán que en lengua vulgar quiere dezir: «jGentes! Ayunat como soleys este mes señalado para que ganeys la gloria»" (libro 939 [1609] 35).

La música acompañaba también a los rituales relacionados con la muerte. Carlos Belvis fue acusado porque se halló en unas setenas de un difunto donde "rezó con otros algunas açoras del Alcorán y se cantaron cantares en alabança de Mahoma” (libro 939 [1609] 43).

\section{HUMOR, BROMAS Y BURLAS}

Entre las manifestaciones culturales de sociedades pasadas una de las que resulta difícil de rastrear es el sentido del humor: ¿qué cosas provocaban la hilaridad entre los miembros de una comunidad? ¿Qué tipo de bromas eran socialmente aceptables y cuáles no? ¿Cuál era la forma de manifestar una broma o un chiste?

Por los datos que he podido recoger parece que la comunidad morisca valenciana gastaba un humor irónico basado a menudo en el juego de palabras. Sus bromas rayaban con la provocación cuando sus autores jugaban con su supuesta ignorancia. El mismo Ignacio de las Casas hace notar que "por mofarse [...] dizen diabólicas al·lusiones en que parece corresponden los vocablos castellanos à su lengua y aún a la nuestra, como por decir Jesús dicen Chiehigi que quiere dezir "gallinas», y quando en Valencia oyen dezir «Senyor ver Déu», que es «Señor verdadero Dios» nombrando al sacramento de la Eucharistía, se mofan con risa porque en su lengua verdeu es el rocín o mulo: y como por dezir «sanctificado sea el tu nombre» dizen sancto peccado seas tú hombre, y por dezir «vernà a juzgar los vivos y los muertos», dizen vernà a jugar los huevos y los guertos: con otros muy peores: y si los reprehenden se escusan con que ni saben ni entienden lo que se dizen y se hazen" (f. 22 v).

Masmuda, del lugar de Almiserà, le dijo a uno que "como el testigo sería buen moro, así sería ella buena cristiana". La amenazaron con que la acusarían a la Inquisición y contestó que "así vería Valencia” (libro 937 [1590] 238).

Joan Pini, Miguel Álvaro y Joan Álvaro, vecinos de Gea de Albarracín, jugaban "con opprobio a un juego que dezian «adórote Señor San Salvador» estando uno sentado, viniendo otro de rodillas y con un paño mojado dava al que estava sentado en el rostro diziendo "adórote señor san salvador»" (libro 936 [1572] 70). 
Joan Faneca, de Alfara de Algímia, dijo que plantaría los árboles "y prenderían como de mano de alfaqui". Ante la Inquisición dijo que lo de los árboles lo había dicho "en chacota" (libro 939 [1609] 19).

Algunas acusaciones son el resultado de haber gastado una broma pesada. Luis Dafell, sombrerero, cristiano viejo del arrabal de Gandía, después de la cuaresma de 1580 acusa a su vecino morisco Jerónimo Solas, "el qual en una botica donde él haze peynes para texer lienço, un día de sábado [...] combidó a éste; y éste le dixo que qué tenía que comer, y el Solaz le dixo que toñina con pebrada y este testigo alargó la mano y tomó un bocado y vio que era hígado de carne y apartóse y echólo de la boca" (554/23). Hacerle comer carne en cuaresma a un cristiano era el equivalente recíproco de tantos apremios cristianos para hacer comer a los moriscos durante los días de ramadán; pero las relaciones de poder entre ambas comunidades no eran simétricas.

Juan Picadura, que estaba preso en la cárcel de Alzira, compartía celda con un cristiano viejo que tenía una grave enfermedad de la que murió. Invocaba éste diversas veces a nuestra señora del Puig, que le ayudase; y según los testigos "como lo oyese el reo dijo «Madre de Dios del Puch, arra el cachuch» lo qual dixo con grande desvergüença y los dos testigos dizen que sabían y entendían el algaravía, que las dichas palabras querían dezir «Madre de Dios del Puch, dadme el coño»; se rió y no quiso pedir perdón" (libro 938 [1608] 438). Nótese que la base de la broma es una palabra que permite hacer un pareado rimándola con otra obscena, en este caso en árabe, jugando con ambas lenguas.

Los signos de que está hecha la cultura son producto de la capacidad simbólica humana, que atribuye cierta carga semántica a determinados objetos, gestos o colores. Pero esas asociaciones simbólicas sólo son significativas para el grupo que ha creado el sistema, y no son las mismas en todas las culturas. Una diferencia entre musulmanes y cristianos es la veneración por parte del mundo cristiano de la cruz y de estampas o figuras de bulto que representan la divinidad y los santos. Para los musulmanes no son más que materia carente de contenido simbólico y pueden ser objeto de burlas y bromas. Francisco Carmidi, de Alasquer explicaba muy bien la diferencia entre la fe musulmana y la cristiana. Decía: "los moros bien creemos que hay un Dios, pero no creemos en la Yglesia de los christianos, ni en los evangelios, ni en la cruz, ni en las ymágenes que los cristianos adoran, ni en la madre de Dios..." (libro 936 [1572] 66).

María Caten, de 15 ó 16 años, vecina de Benimàmet, mujer de Joan Micó, cuenta que "los días pasados ésta compró una imagen de Nuestro Señor y otra de Nuestra Señora y las puso en una pared de su casa; entrando en ella María Casquet, hija de Casquet el viejo -mujer de Frances Micó [hermano de su marido]- y viéndolos allí dixo a ésta que para qué tenía allí aquellos papeles, que cada bez que alçase los ojos a mirallos vería al diablo; y ésta le dixo que ella no lo avia comprado por Diablo sino por cosas de Dios" $(554 / 15,1589)$. Dentro del capítulo de las bromas irreverentes podemos citar el caso de Pedro Muça, de Zarra, que según la acusación "meó en la cara a una imagen de santo y le dijo que beviese" (libro 939 [1609] 37). 
Las cruces eran un elemento de conflicto constante. Para los moriscos la cruz no tenía significado; era, simplemente, un trozo de madera. Lloponi de Benieto, mientras trabajaba en una heredad suya dijo: “¿A quien diablos adoráis bosotros? A un palo" (libro 937 [1590] 233); Pedro Calderer de Oliva dijo que los cristianos adoraban "a un pedaço de palo, diçiéndolo por un cruzifixo" (libro 937 [1593] 539); Miguel Melich de Onda dijo (en algaravía) “que la cruz era un palo" (libro 918 [1600] 215).

Pero eran conscientes del valor que le daban los cristianos, que además habían sembrado de ellas lugares y caminos. Juan Borrido, de Navarrés, "al llegar a una de las dos cruces que hay en el camino tiró de la espada corta que trayha al costado y tiró de revés una cuchillada a la cruz que la echó siete o ocho pasos por tierra". Explica luego que lo hizo estando borracho, que la cruz "era de caña y no de madera y que estava poco fixa en la tierra porque no era sino señal para que no pasasen por allí" (549/ 14, 1573).

Muchos procesos informan cómo un morisco "arrancó una cruz de madera y la hizo pedaços y la echó en un estanque de agua" (Gaspar Alfarra, de Tales, libro 936, 1570); otro "en la yglesia de Alçira había echo pedazos un cruçifixo y dicho muchas blasfemias y heregías" (Miguel Guillén, de Alasquer, libro 938 [1597] 53); el hijo de Joan Bamer, "dio de palos a una cruz del camino saliendo de Castellón” (libro 937 [1590] 225); Gaspar Melon, de Vilallonga, "tiró una piedra a una cruz del camino" (libro 937 [1590] 414); Joan Burrido, de Navarrés, estaba preso "por haber acuchillado a una cruz" (libro 936 [1574] 105); Miguel Boronbon de Yátova, “tiró una piedra a una cruz y después quiso derribarla" (libro 938 [1599] 77); Miguel Fandaix, de Beniopa "quebró una cruz y le dio de puntapiés" (libro 937 [1592] 462). No falta el que estaba acusado de arrastrar una cruz ignominiosamente con mucho escándalo de las personas que lo vieron (Tomás Posanquet, de Alfulell, libro 939 [1609] 41), como hacía Miguel Muza que "quando era justicia traya la cruz del palo por tierra" (Chiva [s.a. ] 553/15).

Algunos son más osados. Abrahim Gualip, de nombre cristiano Joan Royo, vecino de Montroy, fue acusado de haber "escalado el castillo del lugar de Dos Aguas y en él haver hecho pedaços una cruç y hurtado unos corporales y echado por el suelo un ara consagrada" (libro 936 [1573] 77). Hieronimo Lindi, de Benimantell, estaba "indiciado de haber scripto en una pared que una cruz que allí estava estaría bien en las partes posteriores de un perro" (libro 936 [1576] 140).

Algo similar ocurría en relación con el sacramento cristiano de la comunión: la mujer de Chiquet, de Piles, dijo que "en la misa lo que alçava el sacerdote no hera Dios sino un papel" (libro 937 [1590] 231) y Ángela Malop, alias Parreta, de Ayacor, llamó al santísimo sacramento "papelillo" y preguntaba cómo es que no se lo daban a los moriscos (libro 938 [1608] 494). Joan Ramon Melin, de Bétera "volvió la espalda al Santísimo Sacramento y dixo que aquello era Mariváñez” (libro 938 [1604?] 261). 
Otro tema conflictivo era el de la virginidad de María, hasta el punto de que los moriscos podían hacer afirmaciones que no se ajustaban a la doctrina del Islam con tal de llevarles la contraria a los cristianos viejos que les importunaban y presionaban. Muchas de las frases que hemos recogido anteriormente y otras que veremos a continuación son exabruptos y malas contestaciones fruto de provocaciones. Así Matheo Xebis, de Gandía, "no quiso dar limosna por Nuestra Señora; por amor del diablo la daría" (libro 937 [1591] 411). Un vecino de Tales, "diciéndole la embajada que el ángel San Gabriel avia hecho a Nuestra Señora, respondió que Mahoma avía hecho la embajada" (libro 937 [1575] 752).

A Gaspar Habrahan, de Albayda, tres testigos le acusan de que, estando "cantando uno de los testigos las coplas de la anunciación de Nuestra Señora, comentó que quedó preñada del rocín" (libro 936 [1581] 297). Recordaremos la similitud que tanta gracia les hacía entre "ver Déu" y birdawn, rocín. Asociación que pudo inspirar también la ocurrencia de otro que dijo que "la virgen no podía ser virgen, como burra no podía parir sin burro" (libro 938 [1608] 439).

El tema de la virginidad de María surgía constantemente, y su negación por parte de los moriscos no estaba relacionada tanto con la concepción como con el parto: Maria Dynavil, de Benieto, dijo que "si la virgen había parido por donde ella, no podía ser virgen" (libro 937 [1592] 465); Ysabel Joan, de Simat, dijo "que la virgen no podía ser virgen" (libro 937 [1592] 465); la mujer de Torralvi, de Benieto, mientras estaba con un grupo cogiendo olivas, dijo que "si Nuestra señora había parido por donde ella, que no podía ser birgen, e que si lo era, pariría por la rodilla" (libro 937 [1590] 233); Francisco Marquina alias el Africano, vecino de Gea de Albarracín, dijo que "la virgen parió por debajo del braço" (libro 938 [1607] 360); Isabel Payporreta, de Bolbayt dijo "que la virgen parió por la boca; y Cristo no murió y resucitó, sino que se durmió y despertó" [libro 939 (1609) 12].

Las bulas -que consistían en beneficios espirituales a cambio de contribuciones económicas- no gustaban ni a moriscos ni a cristianos por su carácter de imposición pecuniaria. Además ya el propio nombre "bulas" se prestaba a broma y era muy habitual que unos y otros las llamaran "burlas". Hablaba contra ellas Ángela Adari, del arrabal de Cocentaina (libro 938 [1604] 235). Hierónyma Chica, de Sumacárcel, opinaba que "las bullas y jubileos eran cosas de ayre y que todo era burla" (libro 939 [1609] 33). Francisco Tartalico, de Algimia de Alfara, dijo "que las bulas no aprovechan nada; no son gloria sino mierda; y dijo burla en vez de bula" (libro 938 [1604] 219). De la misma opinión era el cristiano viejo Marco Antonio Font, alguacil real extraordinario, vecino de Valencia, quien criticó la bula y añadió "que se cagaba en la cruzada" (libro 938 [1604] 229). 


\section{INSULTOS, MALDICIONES}

Los insultos son un rasgo cultural que refleja los valores de la comunidad que los genera; tienen la finalidad de herir psicológicamente al otro. En el caso de los moriscos, deberemos distinguir los insultos que dirigen a sus correligionarios de los que destinan a la comunidad cristiana; lo mismo vale a la inversa.

Vemos que los cristianos insultan a los moriscos llamándoles "moro", pero el insulto sólo ofende al que no lo es. Cuando a Melchor Torralvi, de Alquerieta, un cristiano le llamó moro, dijo: "honrra es que me hazes en dezirme moro" (libro 937 [1590] 237). Varios moriscos y cristianos viejos estaban haciendo leña en el monte, cuando llegó otro cristiano viejo y empezó a burlarse de los moros y llamó "Mahoma" a Frances Conde, de Faura. Éste respondió "que le alabava en ello, que Mahoma era santo y estava en el cielo" (libro 938 [1599] 55). A Ginés Ardit, de Finestrat, le dijeron: "«Vete que eres un puto moro»; respondió: «puto mentís, moro sí»" (libro 939 [1609] 15).

Los moriscos hacían lo mismo: Ángela Faxarda, de Bétera, insultó a uno llamándole "cristiano" (libro 938 [1597] 39). También servía para ofender a los cristianos llamarles "judíos" y "luteranos". En 1568 el rector de Chelva, el justicia y otros dos hombres desenterraron a una difunta que los moriscos habían enterrado según el ritual musulmán, la amortajaron y la enterraron de nuevo como cristiana en otra sepultura. Entre tanto se habían congregado en un alto del pueblo unos ciento cincuenta moriscos, algunos de los cuales plantaron cara al rector y se organizó un tumulto con pedradas y gritos que acabó con media docena de moriscos detenidos. Los moriscos les gritaban desde lo alto "putos, judíos, luteranos y en algaravía dezian con grandes alaridos lilili o lululu, que no sabe qué quiere dezir" (553/3).

Los insultos no religiosos corresponden a la lengua de la época. Los más usados son "perro" y "bellaco" que equivale a malo y ruin. De un morisco que había confesado en la Inquisición, la mujer de Escuder, de Gandía, dijo "muera el bellaco couarde" (libro 937 [1590] 233). Al reconocer las autoridades la ropa que traía vestida Gerónimo Suleymen, de Buñol, hallaron unos papeles envueltos en un pedazo de lienzo que se los habían descosido de la ropilla. El morisco dice que "nunca vio los papeles ni sabe lo que eran ni si él los traýa consigo; se los habría cosido en la ropilla algún bellaco" (555/21, 1602). Jerónimo Çohot vecino de Yátova cuenta que "en el año de 1571 se fue a bivir a Maniçes usando el officio de labrador, adonde estuvo quatro años y por un bellaco de un señor que está allí que quiso deshonrar su casa se bolvió a Yátova avrá dos años" (556/19). A María Redonda, de Petrés, le encuentran unos papelitos escritos en árabe dentro de la calza. Dice que "no llevava consigo ésta nada ni sabe lo que havía en el emboltorio sino que los guardias son grandes vellacos" (554/21, 1602).

Para ambos grupos era reprobable robar, consumir vino en exceso y renegar de la propia fe. Gaspar Escuder, del Real de Gandía, dijo que los que se venían a diferir al Santo Oficio eran "ladrones y borrachos" (libro 937 [1590 451). Un 
cristiano viejo le enseñaba las oraciones a una hija de Pedro Unqui, de Corbera; éste dijo "que para qué le mostravan semejantes borracherías" (libro 937 [1593] 541). La madre de Pedro Hilel, de Las Almoinas, dijo que los que se venían a diferir al Santo Oficio "eran unos perros renegados" (libro 937 [1592] 477). Ysabel Gato y su marido Francisco Açan, de Matet, trayendo una hija suya una cruz en el rosario le dijeron "que traya la cruz de los perros" (libro 937 [1593] 539 y 552).

A Pedro Maymonet, de Bechí, le dijeron que a su hermano no le sabía mal el tocino. Respondió "que su hermano era un belitre" (libro 937 [1593] 544), término que significa "desvergonzado y sin escrúpulos".

Esperança Çohot, de Yátova, niega el testimonio de quien la acusa, diciendo que "miente como cornudo bujarrón" (556/17, 1602). Bujarrón, sodomita, no era tan fuerte como "cornudo" que según el contemporáneo Covarrubias era un insulto gravísimo; "una de las cinco palabras injuriosas que obligan a desdezirse dellas en común", o sea en público.

Entre las expresiones de maldición que he encontrado en la documentación inquisitorial, la más suave consiste en enviar lo que sea al diablo. Miguel Xaraca Mahusa, vecino de Segorbe, dijo refiriéndose al Ramadán: “iAl diablo el ayuno y quien acá le traxo, que ha de estar el hombre todo el día muerto de hambre!" (552/41, 1579).

Ya es más grave desear la muerte a alguien; la mujer de Escuder, de Gandía, dijo de un morisco que había confesado en la Inquisición: “imuera el bellaco couarde!" (libro 937 [1590] 233).

La pena más terrible a la que alguien podía ser condenado por la Inquisición en aquella época era a ser quemado vivo. De ahí que ésta sea una de las maldiciones más frecuentes: Angela Palaua Mallorquina, viuda de Miguel Mallorquí de Mislata, dijo de cierto inquisidor "que ella lo viese quemado vivo" (libro 938 [1604?] 283). Un cristiano viejo trataba de la misa a Joan Muça, de Jalance; éste dijo en árabe: "iquemados seáis vosotros y la misa y quien a vosotros os tiene aquí!" (libro 938 [1604] 219).

Por último, como maldición, podemos ver el deseo de la mala muerte. Genís Mostacan, de Oliva, había dicho: "vosotros amáis a Jesús y aborrecéis a Mahoma y nosotros amamos a Jesús y amamos a Mahoma". Pero ante la Inquisición dijo que era mentira: él creía en Jesús "y a Mahoma le den mil puñaladas" (libro 938 [1608] 440).

\section{FUENTES DOCUMENTALES}

Archivo Histórico Nacional (Madrid), Sección Inquisición. Valencia. Las referencias a las causas de fe aparecen entre ( ) y remiten a libro [año del auto] y folio. Las referencias a los procesos aparecen entre ( ) y remiten a número de legajo / número de expediente; sigue el año. 
CASAS, I. de las (1605), Información acerca de los moriscos de España: dada a nuestro sanctissimo Padre Papa Clemente Octavo por el Padre Ignacio de las Casas de la Compañía de Jesús: este año de mil y seiscientos y cinco, British Library mss., Add. 10.238.

\section{BIBLIOGRAFÍA}

Barceló, C. (1984), Minorías islámicas en el País Valenciano. Historia y dialecto, Valencia-Madrid.

BARCeló, C. y LABARTA, A. (1984), «Azúcar, “trapigs” y dos textos árabes valencianos», Sharq al-Andalus. Estudios árabes, 1, pp. 55-70.

BARCELÓ, C. y LABARTA, A. (1985), «Indumentaria morisca valenciana», Sharq alAndalus. Estudios árabes, 2, pp. 49-73.

BARCELÓ y C., LABARTA, A. (1987), «Fondos documentales árabes de la minoría musulmana en tierras valencianas», Sharq al-Andalus. Estudios Árabes, 4, pp. 101-107.

BARCELÓ, C. y LABARTA, A. (1987-1988), «Nuevas recetas médicas de moriscos valencianos», Dynamis, 7-8, pp. 347-354.

BARCeló, C. y LABARTA, A. (1988), «Los documentos árabes del Archivo Municipal de Novelda (Alicante)», Saitabi, 38, pp. 119-139.

BARCELÓ, C. y LABARTA, A. (1991), «La industria azucarera en el litoral valenciano y su léxico (siglos XV-XVI)», Actas del Segundo Seminario Internacional "La caña de azúcar en el Mediterráneo" (Motril, septiembre 1990), Motril, pp. 73-103.

BARCELÓ, C. y LABARTA, A. (1996), «Latín y romance en oraciones cristianas halladas a moriscos valencianos», en Romania Arabica. Festschrift für Reinhold Kontzi zum 70. Geburtstag [Herausgegeben von Jens Lüdtke], Tübingen, pp. 315-324.

BARCELÓ, C. y LABARTA, A. (2005-2006), «Tres cartes àrabs del senyoriu de Benilloba a l'arxiu municipal d'Ontinyent (1513-1516)», Alba. Revista d'estudis comarcals de la Vall d'Albaida, 20/21, pp. 4-23.

BARCELÓ, C. y LABARTA, A. (2006), «Balad al-Munastīr y otros lugares arabófonos castellonenses (siglos XV-XVI)», Boletín de la Sociedad Castellonense de Cultura, LXXXI, pp. 289-304.

Barceló, C. y Labarta, A. (2009), Archivos moriscos. Textos árabes de la minoría islámica valenciana 1401-1608, Valencia.

BARRERA MATURANA, J.I. (2007), «Representación de una mujer morisca en un graffiti del Albayzín (Granada)», Anaquel de Estudios Árabes, 18, pp. 65-91.

BERNIS, C. (1959), «Modas moriscas en la sociedad cristiana española del siglo XV y principios del XVI», BRAH, 144, pp. 199-228.

BERNIS, C. (1962), Indumentaria española de tiempos de Carlos V, Madrid. 
BORONAT, P. (1901), Los moriscos españoles y su expulsión, Valencia, 2 vols.

Caro Baroja, J. (1976), Ciclos y temas de la Historia de España: Los moriscos del Reino de Granada. Ensayo de historia Social, Madrid (2. ${ }^{\text {e ed.). }}$

CASEY, J. (1981), El regne de València al segle XVII, Barcelona.

Corriente, F. (1992), Árabe andalusí y lenguas romances, Madrid.

Covarrubias, S., Tesoro de la lengua castellana o española [según la impresión de 1611 con las adiciones de Benito Remigio Noydens publicadas en la ed. de 1674 de M. de Riquer, Barcelona, 1987].

Domínguez-Ortiz, A. y Vincent, B. (1978), Historia de los moriscos. Vida y tragedia de una minoría, Madrid.

La expulsión de los moriscos del Reino de Valencia, Fundación Bancaza, Valencia, 1997.

LABARTA, A. (1977-1978), «Oraciones cristianas aljamiadas en procesos inquisitoriales de moriscos valencianos», Boletín de la Real Academia de Buenas Letras de Barcelona, 37, pp. 177-197.

LABARTA, A. (1979), «Los libros de los moriscos valencianos», Awrāq, 2, pp. $72-$ 80.

LABARTA, A. (1980), «Cinco documentos árabes de los moriscos valencianos», Awrāq, 3, pp. 110-117.

LABARTA, A. (1980), «Inventario de los documentos árabes contenidos en procesos inquisitoriales contra moriscos valencianos conservados en el AHN de Madrid (legajos 548-556)», Al-Qantara, 1, pp. 115-164.

LABARTA, A. (1981), «Ecos de la tradición mágica del "Picatrix" en textos moriscos», en Juan VERNET (coord.), Textos y Estudios sobre Astronomía Española en el siglo XII, Barcelona, pp. 101-109.

LABARTA, A. (1981), «Textos para el estudio de la terapéutica entre los moriscos valencianos», Dynamis, 1, pp. 275-310.

LABARTA, A. (1981), «Una receta morisca para fabricar jabón», en Juan VERNET (coord.), Estudios sobre Historia de la Ciencia Árabe, Barcelona, pp. 155-163.

LABARTA, A. (1981-1982), «Notas sobre algunos traductores de árabe en la Inquisición valenciana», Revista del Instituto Egipcio de Estudios Islámicos, 21, pp. 101-133.

LABARTA, A. (1982), «Cuentas del tendero morisco Gerónimo Hoix (Gandía, 1587)», Al-Qantara, 3, pp. 135-171.

Labarta, A. (1982-1983), «Supersticiones moriscas», Awrōq, 5-6, pp. 161-190.

LABARTA, A. (1983), «Contratos matrimoniales entre moriscos valencianos», AlQantara, 4, pp. 57-87.

LABARTA, A. (1986), «Algunos aspectos del dialecto árabe valenciano en el siglo XVI a la luz del fondo de documentos del AHN», Actas de las II Jornadas de Cultura Árabe e Islámica (Madrid: 1980), Madrid, pp. 281-315. 
LABARTA, A. (1987), La onomástica de los moriscos valencianos, Madrid.

LABARTA, A. (1989), «La mujer morisca: sus actividades», Actas de las V Jornadas de Investigación Interdisciplinaria I: al-Andalus. La mujer en al-Andalus (Madrid, 1985), Madrid-Sevilla, pp. 219-231.

LABARTA, A. (1994), «Contabilidad del morisco valenciano Josep Malux en los años 1581-1583», Saitabi, 44, pp. 57-71.

LABARTA, A. y GARCía CÁRCEL, R. (1981), «Un fondo de documentos árabes de moriscos valencianos», Actas de las I Jornadas de Cultura Árabe e Islámica (Madrid, 1978), Madrid, pp. 395-399.

LONGÁs, P. (1915), Vida religiosa de los moriscos, Madrid, edición facsímil con estudio preliminar por D. Cabanelas, Granada, 1990.

LuQue, J.; PAMIES, A. y MANJÓN, F.J. (1997), El arte del insulto. Estudio lexicográfico, Barcelona.

Mosterín, J. (2009), La cultura humana, Madrid.

VINCENT, B. (2006), «Elementos de demografía morisca», en El río morisco, Valencia, pp. 17-24.

\section{RESUMEN}

Panorama y análisis de la cultura de los moriscos valencianos, a partir de fuentes documentales, esencialmente inquisitoriales. Reflexiones sobre el alcance del término cultura aplicado a las relaciones entre moriscos y cristianos. Análisis a partir de testimonios de primera mano acerca de la lengua árabe; prácticas religiosas; devoción popular; supersticiones; vivienda; indumentaria y adornos; comida y bebida; familia; diversiones; humor, bromas y burlas; insultos y maldiciones.

Palabras clave: moriscos, Valencia, cultura, lengua, religión, superstición, vida cotidiana.

\section{ABSTRACT}

General description and analysis of the culture of Valencian moriscos, from written sources, mostly from the Inquisition. Some thought on the term "culture" applied to the relations between Muslims and Christians. Analysis, from testimonies, of the Arabic language; religious practice; popular devotion; superstitions; housing; dress and ornaments; food and drink; family; entertainments; humor and jokes; insults and curses.

Key words: Moriscos, Valencia, language, religion, superstition, every day life. 